\title{
Research on the Construction of Fire-Fighting Culture and the Innovation of Management System in Colleges and Universities
}

\author{
Sun Yun you
}

Security Department of China Jiliang University, Hangzhou, Zhejiang, China, 310018

syy_1126@163.com

Key words: Fire-Fighting culture, Subjective responsibility, Management system

\begin{abstract}
The construction of fire-fighting culture in colleges and universities not only depends on the consciousness and responsibility of teachers and students for fire prevention and fire control, but depends on the innovation of management system of fire control equipment as well. The effective interaction of the two is a necessary guarantee for a safe campus. This paper attempts to discuss the innovative mode of collaborative management between the construction of the subjective competence of fire-fighting culture and the management system of fire control equipment for campus security.
\end{abstract}

\section{高校消防文化建设及管理体系创新}

\author{
孙运有 \\ 中国计量大学保卫处,杭州,浙江,中国, 310018 \\ syy_1126@163.com
}

关键词: 消防文化 主体责任 管理体系

中文摘要：高校消防文化建设依赖于师生主体消防意识自觉与责任自律，也取决于消防器材 设备管理体系的创新, 两者的有效互动是平安校园的必要条件保障。本文尝试以消防文化建 设为切入, 探讨平安校园消防文化主体能力建构与消防器材设备管理体系协同管理的创新模 式。

\section{1. 引言}

“消防”一词始于日本江户时代，根植于中国历史长河。之所以如此之说，皆因日本文字 由中国的汉字演变而来。“消防”一词不仅字形与汉字完全相同, 字义也无差别。纵观中国两 千多年的消防文化史，我们也可寻受到些许古时中日文化的交流。孔子的《春秋》及其后人 所撰的《左传》最早打开了国史火灾记录的先河, 突出了以人为本的思想。墨子的《备城门》、 《杂守》、《迎敌词》则呈现了我国早期消防技术规范的萌芽。李悝的《法经》将防范和火 灾治理列入“法”的条文。荀悦的《申鉴。杂言》通过“防为上，救次之，诫为下”的“防患于未 然”思想成就了“保一方平安”的消防文化实践的积淀。我国古代学者对中国消防文化的发展做 出了杰出贡献。以孔子为代表的儒家将消防治理是治国安邦和社会生活不可或缺的重要部分。 儒家经典大量消防文化的记载和阐述，既是中国消防文化的主要源头，也很好地例证了消防 文化支撑中华传统文化的重要组成部分。古往今来，人们秉承“防患未然”的儒家经典哲学思 想，不忘初心，始终坚守防火首位，救火次之的中国传统之哲学辩证。儒家思想的核心是“仁 学”即是孟子所说的“人学”，以人为本的思想既体现了治国安邦中消防文化的人道主义精神, 
强化了消防文化主体构建的主体自律和意识自觉，也强调了器材管理创新的体系化构建。“高 校消防工作存在客观和主观两个方面的主要特点。客观特点指高校消防工作自身存在的特殊 性, 主观特点指消防工作管理对象——师生的消防意识和行为特点。这些特点是影响高校消 防工作有效性的重要因素，是制定相关对策的基础”（袁杰，2006（3）：131-132）。

\section{2. 高校消防文化主体管理能力构建}

消防文化是平安校园建设的主要支撑。随着高校建设规模和速度大幅提升,在校师生人数 也成倍增长。据统计显示, 现在一般高校在校师生大部分都在万人以上, 对于这样一个人员 集中, 仪器设备较多的大学校园, 消防文化呈现其特殊性和必要性。然而, 频繁发生的国内 外大学校园火灾, 动轩将整座图书馆、实验楼付之一炬, 致使许多珍贵的图书、标本及教学设 备严重烧毁,不仅影响了教学科研活动的正常进行，而且还造成了巨大的经济损失甚至威胁到 师生员工的人身生命安全。因此, 校园消防文化建设十分迫切, 也势在必行。文化主体的构 建首先依赖于校园师生的意识自觉与责任自律。根据知网, 以“消防文化”为关键词进行文献 检索统计, 检索到的86篇论文中, 近相关论文 28 篇, 远相关论文58篇。从数据看, 消防文化 研究还并没有引起学者们的更多关注。本课题旨在提出高校校园消防文化主体责任建构以及 消防器材设备管理体系的创新模式, 为平安校园消防安全条件保障提供借鉴。

\section{1消防主体意识自觉与责任自律}

《消防法》明确指出“谁管理, 谁负责”的主体管理责任要求高校的消防管理部门要负责 高校的消防工作。但由于消防工作人员人手不足, 难以应付全校消防器材设备的管理和检查, “安全责任制不明确, 防火管理较差。随着市场经济的发展, 部分学校为追求科研成果而不顾 安全、消防工作也同样得不到落实, 不能真正形成“谁主管, 谁负责”的局面, 消防责任得不 到明确”（李飞、肖洋，2009（10）：88-89）。这就需要高校的消防部门分解消防主体责任, 明确消防器材设备管理职责, 充分调动二级学院和二级单位的积极性, 适时地用“谁使用, 谁 管理” 的办法, 进一步明确二级学院和二级单位在消防安全及器材管理上的责任和义务, 使学 校的消防器材设备始终处于常态化管理之中。在调查中发现, 有些学校还是沿用过去小规模 时的一站式管理模式和方法, 漏查漏报现象时有发生。

校园消防文化氛围不够浓厚，消防文化责任意识不强，高校内部消防器材设备和设施管 理不完善是一种通病。师生自觉爱护消防器材设备和消防设施的习惯还没有养成, 致使消防 设施损坏率较高, 甚至随处可以看到乱丢乱放的灭火器。一方面是因为教育的不足, 主体责 任意识较差, 人为性的损坏较为突出; 一方面或是消防器材设备的质量管理出现了问题, 比 如, 疏散指示灯和消防栓的玻璃破损率较高等等。为了更好管理好高校校园消防器材设备, 就需要加强消防文化建设, 增强主体责任意识。与此同时, 建立一种有效的高校消防器材设 备管理体系, 对高校消防器材设备进行科学和规范化的创新管理十分必要。只有消防文化主 体责任和器材管理体系的互动促进, 才能真正实现消防安全, 为平安校园提供条件保障。

\section{2消防器材设备的规范化管理责任}

高校消防器材设备是在一旦发生火灾后, 扑灭初起火灾的最有效的灭火工具。而消防器 材设备的管理, 就是要使消防器材设备始终保持一种良好的有效性和正常的工作状态, 以便 随时发挥其作用, 以减少火势蔓延所带来的财产和生命损失。因此, 消防器材设备体系化管 理是在关键时刻充分发挥消防器材设备有效灭火作用的基础。随着高校近些年来的快速发展, 校园建设和招生人数日益扩大，高校消防器材设备的投入和配备也随着校园的不断扩大而增 加。高校消防器材设备配备也具有了多元化和点多面广的特点。在管理人员有限的情况下, 容易出现管理上的不到位, 失效器材查不到, 不能及时更新的情况, 也是客观的、不可回避 的事实。 
消防器材设备规范化管理是一种动态性管理, 而非一劳永逸的事情, 决不是把器材配备 好了就算完成任务, 完事大吉。按照《消防法》的要求, 消防器材设备需要定期进行检查, 逐一核实。消防器材设备之所以动态管理是出自其诸多的主客观原因。比如, 消防器材设备 被人为的移位, 也有的被人拿走, 还有的被好奇心强的人操作过; 又或是消防器材设备质量 的客观原因及日久天长而形成的自然性失效和老化。这些原因都可能带来消防安全隐患。要 做到动态性管理, 就必须建立一本清晰的消防器材设备台帐。但遗憾的是, 大部分高校的消 防器材设备台帐或多或少都存在有规范缺陷。大多高校都是委托公司维保供应和更换消防器 材设备, 尤其是灭火器换装药。由于学校没有储备灭火器, 当楼内灭火器在拉走换药时, 楼 内就会出现灭火器配备空档, 假如此刻发生火情, 后果相当严重, 同时也会出现消防安全责 任事故，会给学校和师生造成不良影响和生命财产安全隐患。

\section{3. 高校消防器材设备管理体系构建}

体系是一个科学术语, 泛指一定范围内或同类事物按照一定的秩序和联系组合的整体。 管理体系也称为体系化, 就是使事物成为体系的过程。因此, 高校校园消防器材设备管理体 系就是要将高校校园内的消防器材设备形成一种较科学的, 有秩序的协同管理的有机整体。 通过建立这样一种体系并进行有效管理来促进高校消防器材设备的完好率的提高。高校校园 消防器材设备管理体系的构建是消防文化建设的主体责任和客体生成的力量凝结。要建立一 种科学的消防器材设备管理体系, 就要从三个方面的因素考虑: 一是文化理念要素; 二是流 程管理要素; 三是责任管理要素。

\section{1消防文化理念要素体系化培养}

高校校园消防文化建设工作，最易建立同时也最容易忽视的就是文化理念要素。因为文 化理念要素往往没有那些管理责任要素来的直接和实在。文化理念要素体系化建设, 往往需 要更多的时间, 形成过程要比管理责任要素的实施过程慢长许多, 故而, 很容易因被阶段化 或过程化而终止。从消防文化建设与管理的意义上讲, 消防器材设备管理的文化理念要素体 系化建设, 乃至在学校校园整个消防管理工作中, 是最符合消防方针的一项内容。消防工作 方针是“预防为主，防消结合”，而这恰恰是一种理念性的和文化性的。“在大学内普及消防安 全教育, 是当前高校安全工作的需要, 是提高全校火灾预防能力的一项群众性基础工作。开 展大学生安全教育是保护在校大学生人身财产安全和合法利益的需要, 具有重要地位和独特 作用”(龙海锋、司敏娜，2008（2）：79-81). 高校消防工作理念的确立和消防文化的形成, 正好与消防工作方针不谋而合, 从而达到预防先行的效果。文化理念要素体系化建设包括有 以下几项建设内容:

(1) 高校校园消防文化理念和消防文化的培养;

(2) 高校校园消防器材设备管理制度的健全与完善;

(3) 高校校园消防器材设备台帐的建立、维护与更新;

(4) 高校校园消防器材设备管理激励机制和惩戒措施。

\section{2消防流程管理要素体系化建设}

高校校园消防器材设备的流程要素管理，除了固定位置器材设备管理，还存在有流动性 器材设备管理, 消防器材设备管理的体系化建设就是要求我们既要做好固定位置器材设备管 理, 同时也要做好校园内部的消防器材设备流动过程中的管理。消防器材设备的缺失和丢失, 大多是发生在流动性管理之中。因此, 在建立校园消防器材设备管理体系时, 就要充分考虑 流程要素体系化建设问题, 以确保消防器材设备在流动性管理中的不丢失和不损坏。消防器 材设备管理流程要素体系化建设应包括:

（1）消防器材设备采购合同与标准管理; 
（2）消防器材设备供货管理与质量监督;

(3) 消防器材设备出入库管理与主体责任;

(4) 消防器材设备配置与维护验收管理。

\section{3消防责任管理要素体系化建设}

高校消防器材设备管理体系中的责任管理要素体系化建设就是消防文化的强制性责任建 设, 指看得见的, 为做好消防设备器材管理而建设、细化、完善的各级组织, 包括人员的到 位。因此, 这是高校消防器材设备管理体系化建设中的关键。“责任制度逐级落实”是高校消 防安全管理体系正常运作的关键。从建立消防安全组织、健全消防安全制度、强化责任追究 制度等几方面来做到“责任制度逐级落实”(贾水库等，2008（8）：129-131)。因此，在责任 管理要素体系化建设中, 要改变高校现有的消防器材设备一站式管理模式, 实现阶段控制, 三级联管的管理模式。阶段控制是指：采购阶段，把好标准质量关; 出入库阶段，把好数量 关; 配置、维护阶段，把好验收关。三级联管是指：学校保卫消防部门：负总管。负责消防 器材设备配备, 按照要求计算不同场合需要配置消防器材设备的数量和型号; 督促检查、巡 查消防器材设备和设施的完好率; 及时更换和维护消防器材设备和设施; 发放消防器材设备 检查记录卡和记录本; 定期排查整个校园的消防安全隐患; 负责与公安消防部门沟通与联系。 二级学院和二级单位（消防安全管理人）：负责本单位所辖区域内所有消防器材设备的检查 和管理; 及时报告需要维护的消防器材设备和设施; 填写消防器材设备月检记录。实验室负 责人 (重点岗位人员) 或消防义务员负责消防器材设备的日查; 填写消防器材设备检查记录 卡; 及时报告消防器材设备完好情况。

高校校园消防器材设备管理体系的责任管理要素, 就是要从组织和人员确定与责任上, 确立消防器材设备的常态化管理, 以保证全面、细致、不留遗漏的消防器材设备的日常化检 查, 使消防安全隐患无处存在。

\section{4. 高校消防器材设备管理体系化实施}

高校在消防器材设备体系化管理尚不很成熟, 管理中沿用的传统性的方法较多, 创新性, 系统性还有待于进一步的加强。“消防安全网格化管理就是进一步细化各部门、各校领导、各 人的工作职责, 增强责任意识, 从整体到个人, 从上层领导到基层教师, 将每一部门, 每一 个学生纳入消防安全体系。这一理念的提出具有重要的意义”（朱芳、冯伟明, 2012(8): 240-242）。网格化管理是进一步改进工作作风、转变高校校园消防器材设备管理体系的建立, 恰恰弥补了管理体系上的不足，将管理中的文化意识、流程管理、责任管理三个要素紧密联 系聚合在一起，使其能在一个庞大的系统中运行，互为作用，有效促进，集分散管理、单个 管理为科学化和系统化管理是平安校园消防文化建设的有力措施保障。

高校校园的消防器材设备管理的成效如何, 将直接影响校园初起火灾的扑灭程度。因此, 在高校校园消防器材设备管理上要引起每一位师生的重视和关注。消防器材设备管理体系的 实施, 关涉诸多单位、部门和人员, 所以在实施过程中还需要高校领导的重视和引导, 光靠 保卫消防部门, 不太容易形成体系化的操作和联动。因为, 在体系化运行过程, 师生主体发 挥着重要的能动作用, 其中, 更重要的是消防文化理念、责任义务和积极行为的相互支撑。 消防文化理念的养成依赖于平时的消防责任工作的落实及经验积累。没有平时辛勤的工作， 体系中的任何环节就可能会自然脱节; 某一项工作的终止, 都会导致整个体系的瘫疾。这也 说明在这个体系中消防文化理念要素的重要性。因此, 在消防文化体系建设中, 要充分做好 消防意识自觉和责任自律的思想教育工作, 才能充分提高校园消防器材设备管理的效能, 促 进校园消防文化建设的发展。 


\section{5. 结语}

本文从平安校园的视角, 探讨了消防文化建设中的主体意识和责任构建以及与消防器材 设备体系化管理能力之间的关联互动、相互促进的创新管理模式。师生是消防文化建设的主 体, 文化自觉与责任自律是平安校园的积极主体保障。高校消防文化建设体系化建设中文化 理念要素、流程管理要素、责任管理要素的聚合支撑及有效实践是平安校园建设的基本条件 保障。高校校园消防文化建设中“预防为主，防消结合”理念性和文化性要素的生成及体系化 机制及科学规范将消防文化管理主体和消防器材设备管理有效凝结, 真正落实平安校园消防 安全。

\section{References}

[1] Jie. Yuan, On the Features and the Strategies of Fire Prevention at the Universities, Journal of ChiFeng College,(Soc.Sci), vol.27, No.3, pp.131-132, 2006.

[2] Fei.Li \& Yang. Xiao, Fire Accidents at Universities and Fire Safety Management on Campus, Pioneering With Science and Technology Monthly, vol. 10, pp. 88-89, 2009.

[3] Haifeng. Long \& Minna. Si, Discussion on the Present Situation and Countermeasures for the Security of Fire Prevention at Universities, Journal of Huanggang Polytechnic, vol.10, No.2, pp.79-81, 2008.

[4] Shuiku.Jia \&Xingde.Liu \&Sijing.Cai, Research on the Construction of Fire Safety Management System in Colleges and Universities, Journal of Safety Science and Technology, vol.4, No.8, pp. 129-131, 2008.

[5] Fang.Zhu \& Weiming.Feng, Research on Grid Management System of Fire Safety in Colleges and Universities, Industrial \& Science Tribune, vol.11, No.8, pp. 240-142, 2008. 